\title{
Assessing the Health of Akamkpa Forest Reserves in Southeastern Part of Nigeria Using Remote Sensing Techniques
}

\author{
Elijah S. Ebinne, Ojima I. Apeh (D), Raphael I. Ndukwu, and Edebo J. Abah \\ Department of Geoinformatics \& Surveying, University of Nigeria, Enugu Campus, Enugu, Nigeria \\ Correspondence should be addressed to Ojima I. Apeh; ojima.apeh@unn.edu.ng
}

Received 18 November 2019; Revised 10 June 2020; Accepted 20 June 2020; Published 27 July 2020

Academic Editor: Nikolaos D. Hasanagas

Copyright (c) 2020 Elijah S. Ebinne et al. This is an open access article distributed under the Creative Commons Attribution License, which permits unrestricted use, distribution, and reproduction in any medium, provided the original work is properly cited.

\begin{abstract}
Assessment of forest health is very vital because forests form the largest terrestrial ecosystems on earth. The greenness of vegetation is one of the essential factors used in evaluating the health of forest reserves. This study is aimed at assessing the health of fifteen forest reserves in Southeastern part of Nigeria using meteorological data and MOD13A1-derived Normalized Difference Vegetation Index (NDVI) and Enhanced Vegetation Index (EVI). Related portions of the monthly MOD13A1 data, derived for the years 2010, 2014, and 2018, were downloaded, and the monthly mean values of the vegetation indices (NDVI and EVI) were estimated for each of the forest reserves using the Spatial Analysis Module in ArcGIS software. The computed monthly mean values of NDVI range from $\mathbf{0 . 0 9 4}$ to $\mathbf{0 . 7 9 0}$ while that of EVI ranges from $\mathbf{0 . 1 1}$ to $\mathbf{0 . 6 2 4}$ and the rainfall data range from 0 to $780.2 \mathrm{~mm} /$ month within the period of study. Analyses of the correlation coefficients between monthly rainfall data and NDVI, monthly rainfall data and EVI, and that of NDVI and EVI range from -0.827 to $0.584 ;-0.715$ to 0.914 , and 0.598 to 0.980 . The obtained results indicate that some of the forest reserves are moderately healthy while some areas are under great stress. We can conclude that satellite remote sensing is a veritable tool in the assessment, management, and monitoring of forest health especially where there is little or no terrestrially acquired forest inventory data.
\end{abstract}

\section{Introduction}

Forest health in Cross River State (a State in Southeastern Nigeria) is threatened by so many factors such as colonial nationalization and commodification of the forest estate, agricultural practices, government plantations and deforestation, uncontrolled extraction of nontimber forest products (NTFPs), highway construction and mining of solid minerals, dereservation of large portions of some government forest reserves, and foresters and resistance to decentralized forest management [1]. Forest health is a condition of forest ecosystem that sustains their complexity while providing for human needs [2]. Healthy forests, which could be assessed and monitored by many forest health indicators, are needed for aesthetical pleasure, satisfaction of human needs, and maintenance of sustainable ecosystem.

It is unarguable that the indicators of forest health obtained from forest inventory programs are more accurate but their acquisition is time-consuming, laborious, and costintensive. To worsen the matter, there is paucity of longstanding and standardized forest health inventory programs in the study area, thereby necessitating the use of remote sensing techniques to assess the health of the forest reserves in Cross River State following the outcry by [1] and the reports from United Nations Programme [3, 4]. This lack of terrestrially acquired forest inventory data makes it impossible to integrate satellite remote sensing techniques with past inventory data in assessing the health of these forest reserves under study in contrary to what is obtainable in some other studies [5-7]. The Normalized Difference Vegetation Index (NDVI) and Enhanced Vegetation Index (EVI) derived from MODIS (moderate resolution imaging spectroradiometer) coupled with meteorological data have been severally used to determine the greenness (which is an indicator of healthy condition) of vegetation in many localities [8-13]. 
Absorption and reflection of photosynthetically active radiation [14] over a given period of time, which is shown by the vegetation indices, can be used to assess the health of forest reserves. NDVI and EVI are vegetation indices used for measuring the greenness of the vegetation. They range from -1 to +1 , and they are very useful in monitoring and understanding environmental and climatic changes. Vegetation indices are radiometric measures of photosynthetically active radiation absorbed by chlorophyll in the green leaves of vegetation canopies and are therefore good surrogate measures of the physiologically functioning surface greenness level of a region (https://climatedataguide.ucar.edu/climate-data/ ndvi-normalized-difference-vegetation-index-3rd-generationnasagfsc-gimms).

The MODIS-derived vegetation indices (NDVI and EVI) have been severally used to analyze the spatiotemporal trends over Southern Asia [8]; extract and understand the phenological information about evergreen, semievergreen, moist deciduous, and dry deciduous vegetation in India [9]; forecast the seasonal crop yield in Canada [15]; identify the corn growth in Western Mexico [16]; estimate the forest productivity and dieback in a Mediterranean holm oak forest [10]; assess the seasonal and potential canopy photosynthesis in relation to seasonal changes in Leaf Area Index (LAI), chlorophyll concentration, and air temperatures of $\mathrm{NE}$ Argentina subtropical forests [11]; quantify the drought intensity and its geographical effects in order to support the drought monitoring applications [17]; investigate the biomass of forest reserve and the periods of vegetation [12]; depict the quality and relative health of a forest reserve [13]; determine the onset of phenophases in spring and autumn and also to assess forest growth and health condition [18]; evaluate the sensitivity of MODIS-based vegetation index to heat and drought stress in temperate forests [19]; and monitor the trends and changes in vegetation and evaluate the proxies for drought conditions [20].

Several other factors can affect forest health and vitality which include abiotic factors (wild or human-induced fires, pollution, floods, nutrients, and extreme weather conditions such as storms, hurricanes, droughts, snow, frost, wind, and sun); biotic factors (insect pests, diseases and invasive species and can either consist of fungi, plants, animal, or bacteria); and human factors (overexploitation, competing land uses, and poor harvesting techniques or management can negatively impact forest ecosystems) [21]. The major reasons for the degradation of the forest reserves under study are deforestation and competing land uses. It is true that the mechanism that determines forest health is complex [22], but in this study, we have chosen to assess the forest health by estimating the greenness (which is a direct measure of photosynthetic potential resulting from the composite property of total leaf chlorophyll, leaf area, canopy cover, and canopy architecture) of vegetation using vegetation indices derived from MODIS data for the years 2010, 2014, and 2018 coupled with monthly rainfall data of the study area.

The premise of the study is that NDVI and EVI are indicators of vegetation health since deterioration and improvement of ecosystem in vegetation is often reflected in a decrease or increase in the value of NDVI and EVI. Holding all other factors that affect vegetation constant, a healthy forest reserve should yearly improve in greenness meaning that the estimated mean values of the vegetation indices should remain the same or increase from year to year. Additionally, only positive values of NDVI should correspond to vegetated zones like the forest reserves [23]. The objectives of this study were to (1) compute monthly mean values of NDVI and EVI from multitemporal MODIS data for each of the fifteen forest reserves; (2) determine correlation coefficients between the rainfall data and the vegetation indices; (3) determine the yearly seasonal variation of vegetation indices; and (4) analyze the computed parameters in order to assess the health of each of the fifteen forest reserves. This study is very important in that it will help in determining whether the forest reserves are actually deteriorating or improving in health and can be applied in the monitoring and management of natural resources against artificial and natural environmental hazards.

\section{Materials and Methods}

The designed workflow of this study is shown in Figure 1.

2.1. Study Site. Cross River State is a coastal State in Southeastern Nigeria and also one of the states within the Niger Delta region. The tropical climate of Cross River State has an average annual temperature and rainfall as $26.1^{\circ} \mathrm{C}$ and $2750 \mathrm{~mm}$, respectively. It lies within latitudes $4^{\circ} 48^{\prime} 45^{\prime \prime} \mathrm{N}-6^{\circ} 52^{\prime}$ $05^{\prime \prime} \mathrm{N}$ and longitudes $7^{\circ} 49^{\prime} 35^{\prime \prime} \mathrm{E}-9^{\circ} 22^{\prime} 05^{\prime \prime} \mathrm{E}$. In Cross River State, there are four synoptic stations of the Nigerian Meteorological Agency strategically located in different regions (Calabar, Ikom, Obudu, and Ogoja) within the state. The coordinates (longitude and latitude) of the four meteorological stations where the rainfall data were obtained from are given as Calabar $\left(8.35^{\circ}, 4.97^{\circ}\right)$, Ikom $\left(8.72^{\circ}, 5.97^{\circ}\right)$, Ogoja $\left(8.80^{\circ}, 6.70^{\circ}\right)$, and Obudu $\left(9.10^{\circ}, 6.61^{\circ}\right)$.

Cross River State has rich natural resources, and among them are huge forest reserves, cutting across various local government areas of the State. Fifteen of these forest reserves (Afi River, Achara Ihe, Agoi, Cross River North, Cross River South, Ekinta River, Gabu, Ikom, Ikrigon, Lower Enyong, Oban Group, Obieze-Isu, Umon Ndealichi, Uwet Odot, and Yache) are considered, and they are referred to as Akamkpa forest reserves in this study. Figure 2 shows the map of Cross River State and the fifteen forest reserves evaluated in this study.

The major activities affecting the health of these forest reserves are deforestation, logging and timber extraction, establishment of tree-crop agricultural plantations (e.g., cocoa, rubber, oil palm, cashew, and gmelina) using the taungya system, construction of highways (e.g., CalabarIkom-Ogoja road, Ogoja-Obudu-Ikom road, Calabar-ObanEkang road, Calabar-Itu-Ikot Ekpene road, and IkangCalabar), mining of solid minerals, farming, extraction of nontimber forest products (e.g., wild edible vegetables, wild edible fruits, medicinal plants, fuel wood, building materials, and arts and craft materials), dereservation of large areas of 


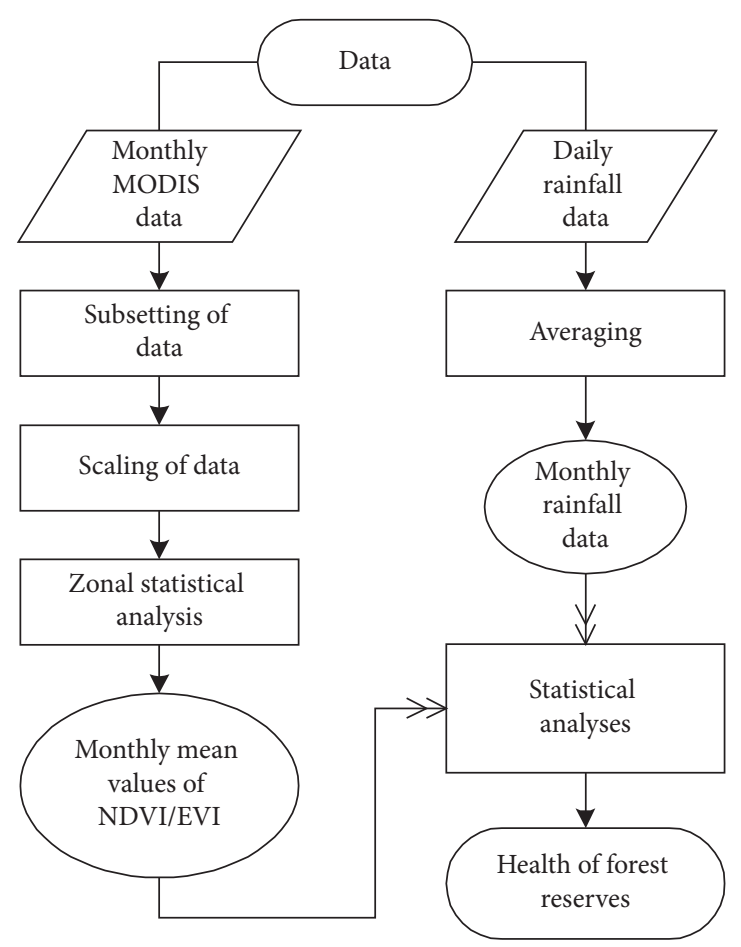

FIGURE 1: Schematic workflow of the study.

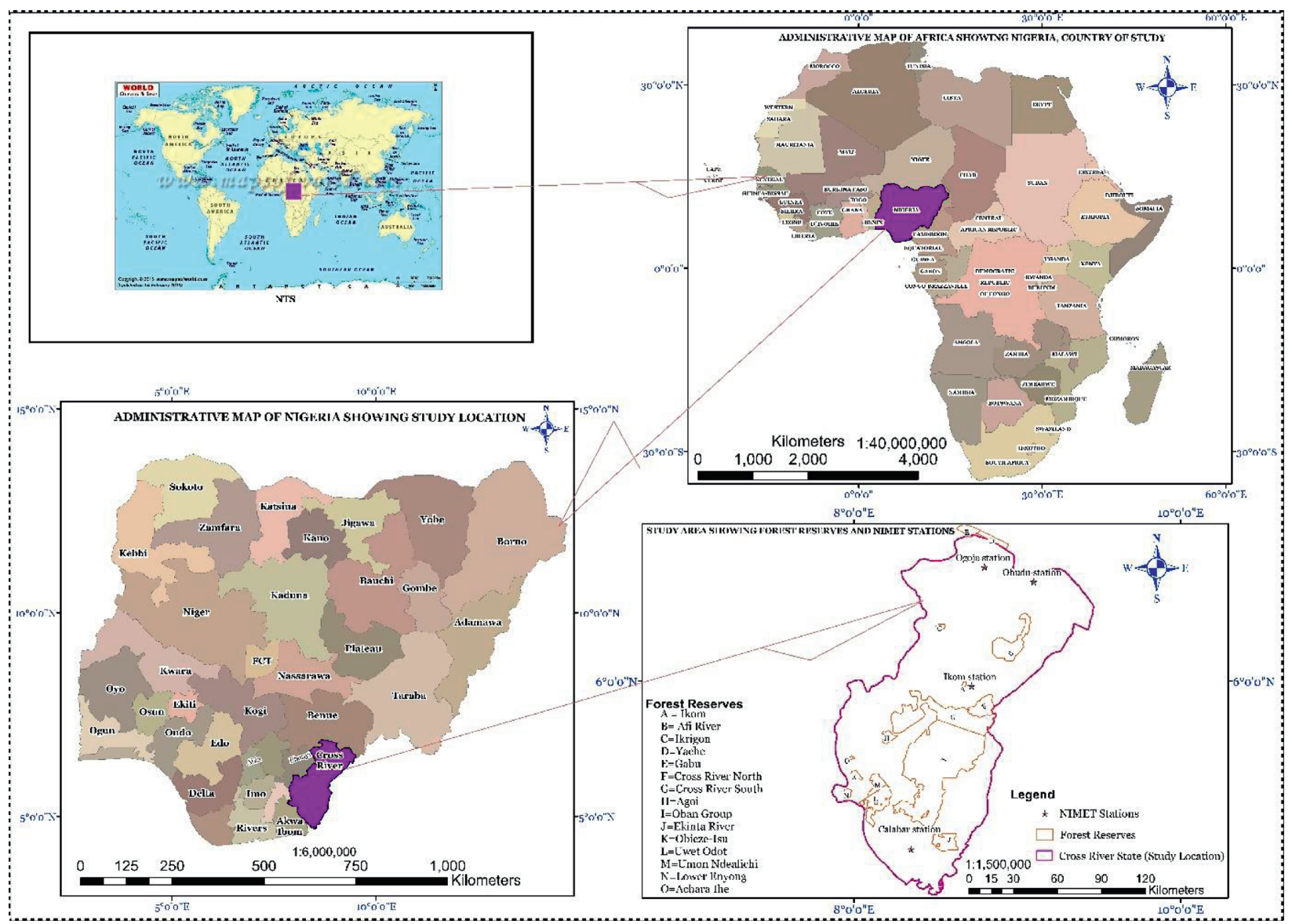

FIGURE 2: Representation of the location site used in the present research. 
certain forest reserves, and rapid urbanization [1, 3]. According to [4], "the main threats to the forest reserves include subsistence and commercial agriculture, fuel wood collection (firewood and charcoal), overharvesting of timber (illegal), forest fires, settlements, and infrastructure development." Exotic tree species like teak and gmelina arborea are found in some of these forest reserves.

2.2. Acquisition and Processing of Satellite Data. The monthly data of MODIS (MOD13A1) of years 2010, 2014, and 2018 were downloaded from NASA website. MODIS images are distributed as hierarchical data format (HDF) with tiles of $10 \times 10$ arc degree and projected in the sinusoidal projection. The geometric correction was applied to reproject the raw data into UTM WGS84 datum. This study used the 16-bit signed integer MOD13A1 for vegetation indices. The blue, red, and near-infrared reflectance (centred at 469 nanometers, 645 nanometers, and 858 nanometers, respectively) were used to determine the MODIS daily vegetation indices. Three different composite sets (8-day, 16-day, and dual-8day composite periods) of 12-month time series MODIS_500 $\mathrm{m}$ NDVI and EVI data spanning from January to December for years 2010, 2014, and 2018 were computed using the Spatial Analysis Module in ArcGIS software in order to analyze seasonal vegetation dynamics and correlation with meteorological data.

The data were imported into ArcGIS 10.1 software for processing. The boundary shapefile of Cross River State was used to subset the global data. The boundaries of the fifteen forest reserves were extracted from the forest reserve map obtained from the State Forestry Commission. The Spatial Analyst Module in ArcGIS Software was used to estimate the monthly mean values of NDVI and EVI of the fifteen forest reserves. The resulting table was then saved in Microsoft Excel for further statistical analyses. The obtained values of NDVI and EVI were multiplied by the scale factor of 0.0001 . The equations used for computing EVI (equation (1)) and NDVI (equation (2)) are $[24,25]$ :

$$
\begin{aligned}
\text { EVI } & =G \frac{\mathrm{NIR}-\text { Red }}{\text { NIR }+C 1 \text { Red }-C 2 \text { Blue }+L}, \\
\text { NDVI } & =\frac{\text { NIR }- \text { Red }}{\text { NIR }+ \text { Red }}
\end{aligned}
$$

where NIR, Red, and Blue are the full or partially atmospheric-corrected surface reflectances and $C 1$ and $C 2$ are the coefficients of the aerosol resistance term (which uses blue band to correct for aerosol influences in the red band)' $C 1=6 ; C 2=7.5$. $L$ is the canopy background adjustment for correcting the nonlinear, differential NIR, and red radiant transfer through a canopy; $L=1$.

2.3. Meteorological Data. The monthly rainfall data of the period under study were obtained from the Data Management Unit of the Nigerian meteorological Agency (NIMET) for the purpose of carrying out trend analysis in relation to the vegetation indices. Casella and Splayed manual rain gauge was the instrument used by NIMET for measuring the monthly rainfall data, and its unit is in millimetres ( $\mathrm{mm}$ ) (https://www.nimet.gov.ng/).

2.4. Data Analysis and Interpretation. The monthly mean values of the vegetation indices were thoroughly examined to see if they are within the range of low or moderate or high vegetation so as to determine the health condition of each of the forest reserves. Vegetation greenness is shown by the mean values of the monthly NDVI. Very low values $(\leq 0.1)$ of NDVI represent the barren areas of rock, sand, or snow while moderate values $(0.2$ to 0.3$)$ represent shrub and grassland and high values (0.6 to 0.8$)$ represent temperate and tropical rainforests $[13,26]$. According to these studies $[26,27]$ mean NDVI for deciduous and evergreen forests should range from 0.42 to 0.51 and 0.52 to 0.69 , respectively. As revealed in an earlier study over a large portion of the Sahel region [23], only positive values of NDVI should correspond to vegetated zones such as the forest reserves. The higher the index, the greater the chlorophyll content of the forest reserves and the healthier the forest reserves.

EVI is directly related to the NDVI and gives more weight to the near-infrared band. The NDVI and EVI are very similar, with the NDVI being directly related to primary production and the EVI being more heavily weighted to the Mapping Leaf Area Index in very dense plant canopies [28]. The advantage of using EVI is that it uses additional wavelengths of light to correct for variations in solar incidence angle, atmospheric conditions like distortions in the reflected light caused by the particles in the air, and signals from the ground cover below the vegetation. NDVI is highly sensitive to soil background and atmospheric effects, while EVI is less sensitive to them, thereby making it to provide a better quantification of vegetation abundance and physiological activity [24, 29]. Overall, the correlation coefficient between NDVI and EVI is expected to be highly positive.

In order to allow for proper assessment of the health of the fifteen forest reserves, the monthly rainfall data and the monthly values of NDVI and EVI were averaged and correlated. Some earlier studies [27, 30-32] have shown the correlation between monthly rainfall data and NDVI. This led to the determination of the coefficient of correlation between the rainfall data and the vegetation indices as a means of externally validating and/or assessing the values of NDVI and EVI. We adopted this approach (using coefficient of correlation) most especially because of the lack of terrestrially acquired forest inventory data in the study area that could further validate the MODIS-derived values of NDVI and EVI. As pointed out in those earlier studies [27, 30-32], which is a means of interpreting the results, NDVI is not immediately responsive to rainfall but tends to lag behind rainfall by one or two months. Thus, rainfall in the concurrent month plus two or more antecedent months were included and examined to determine the correlation with NDVI.

The rainfall data and NDVI and EVI values corresponding to each of the four seasons (winter, spring, summer, and autumn) of the year were extracted and 
averaged so as to assess the seasonal variation of the vegetation indices, thereby determining the health of the forest reserves seasonally. This was done by averaging the rainfall and NDVI and EVI values of the various months (December, January, and February (winter); March, April, and May (Spring); June, July, and August (Summer), and September, October, and November (Autumn)) corresponding to the four seasons.

Assuming all other factors that affect or influence vegetation are constant, it is expected that the estimated mean values of vegetation indices should remain the same or increase from year to year, thereby showing improvement in the health of the forest reserves. One of the ways of interpreting the estimated mean values of the vegetation indices is to determine their percentage change (equation (3)) over the years (2010 to 2014, 2014 to 2018, and 2010 to 2018). The percentage change is calculated as follows:

$$
\text { percentage change }=\frac{\text { current year }- \text { previous year }}{\text { previous year }} \times 100 \text {, }
$$

where current year $=$ estimated yearly mean values of the vegetation indices of the current years (2014 and 2018) and previous year $=$ estimated yearly mean values of the vegetation indices of the previous years (2010 and 2014).

If the percentage change is positive, it means that the forest reserve in question improved in health but if otherwise, then, such forest reserve deteriorated in health within that period.

\section{Results}

3.1. Monthly Mean Values of Rainfall Data and Vegetation Indices. The results of the monthly rainfall data, NDVI, and EVI for each of the years are shown in Figure 3. The results of the monthly NDVI and EVI thematic output maps for years 2010, 2014, and 2018 are also shown in Figure 4. Generally, the monthly rainfall values range from 0 (December, January, and February) to $611.4 \mathrm{~mm}$ (June) for year 2010; 0 (December and January) to $716.2 \mathrm{~mm}$ (July) for year 2014, and 0 (January) to $780.2 \mathrm{~mm}$ (August) for year 2018 .

\subsection{Seasonal Variation of Rainfall Data and Vegetation} Indices. Seasonal variation of each of the fifteen forest reserves with rainfall, NDVI, and EVI of years 2010, 2014, and 2018 is appended (Table S1, Table S2, and Table S3), but an overview is shown in Table 1.

In 2010, the NDVI values at all the four seasons range from 0.246 (Summer; Ekinta River and Obieze-Isu) to 0.646 (Autumn; Ekinta River) while EVI values are from 0.201 (Winter; Gabu) to 0.517 (Autumn; Ikom). In 2014, the NDVI values at all the four seasons range from 0.315 (Summer; Ekinta River) to 0.675 (Spring; Lower Enyong) while EVI values are from 0.194 (Winter; Gabu) to 0.496 (Summer; Ikom). In 2018, the NDVI values at all the four seasons range from 0.431 (Summer; Oban group) to 0.664 (Autumn; Ekinta River) while EVI values are from
0.271 (Winter; Lower Enyong) to 0.466 (Autumn; Ekinta River).

3.3. Yearly Mean Values of Rainfall Data and Vegetation Indices. The yearly mean values of rainfall, NDVI, and EVI as computed are shown in Table 2 .

For 2010, NDVI ranges from 0.404 (Gabu) to 0.555 (Cross River North) while EVI ranges from 0.286 (Gabu) to 0.423 (Ikom). For 2014, NDVI ranges from 0.457 (Gabu) to 0.618 (Ikom) while EVI ranges from 0.293 (Yache) to 0.464 (Ikom). For 2018, NDVI ranges from 0.433 (Yache) to 0.603 (Ikom) while EVI ranges from 0.277 (Gabu) to 0.438 (Ikom).

3.4. Correlation Coefficients of the Monthly Data. Table 3 lists the various correlation coefficients of the parameters (rainfall, NDVI, and EVI) that were examined to determine the health condition of the fifteen forest reserves under study. Corel_RF_NDVI, Corel_RF_EVI, and Corel_NDVI_EVI in Table 3 mean correlation coefficients between rainfall and NDVI, correlation coefficients between rainfall and EVI, and correlation coefficients between NDVI and EVI, respectively.

\section{Discussion}

Based on the index scale of different land areas for vegetation greenness $[13,26]$, the obtained values (Figures 3 and 4 ) indicate that some of the forest reserves are moderately healthy while some are stressed. The various reasons why some of these forest reserves are being stressed have been pointed out in $[1,3,4]$. The major reasons for the degradation of these forest reserves are deforestation and competing land uses. There is no consistent pattern between the values of monthly rainfall data and the vegetation indices for the years 2010, 2014, and 2018. For the multitemporal years $(2010,2014$, and 2018) under study, the overall trend in monthly maximum NDVI is positive over the study area showing the greening of the forest reserves with a net increase in biomass production during the period. This is consistent with earlier study over a large portion of the Sahel region [23].

It was observed (Table 1) that there is a general increase in the mean values of vegetation indices from winter to autumn, and this confirms that the more the rainfall during the preceding season the more the greenness of vegetation during the following season $[23,30,31]$.

Table 2 shows that most of the forest reserves are moderately healthy but some (Gabu, Ikrigon, and Yache) are stressed, judged from the yearly mean values of the vegetation indices obtained. Overall, the obtained mean values of the vegetation indices show the yearly chlorophyll content of each of the fifteen forest reserves. They were expected to remain the same or increase on a yearly basis assuming all factors that affect chlorophyll content are constant.

There is relative agreement between the values obtained from the percentage change (Table 4) in NDVI and those of EVI within the period of 2010-2014, but a general disagreement (which could be as a result of high 

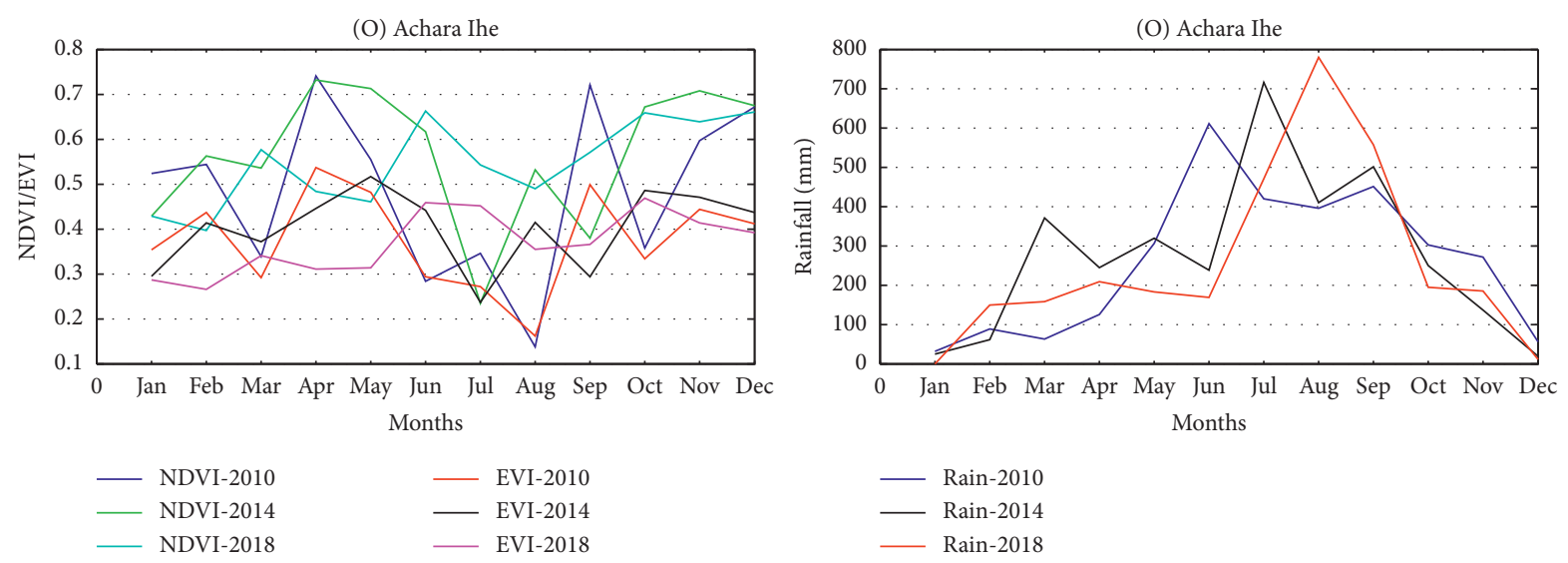

(B) Afi River
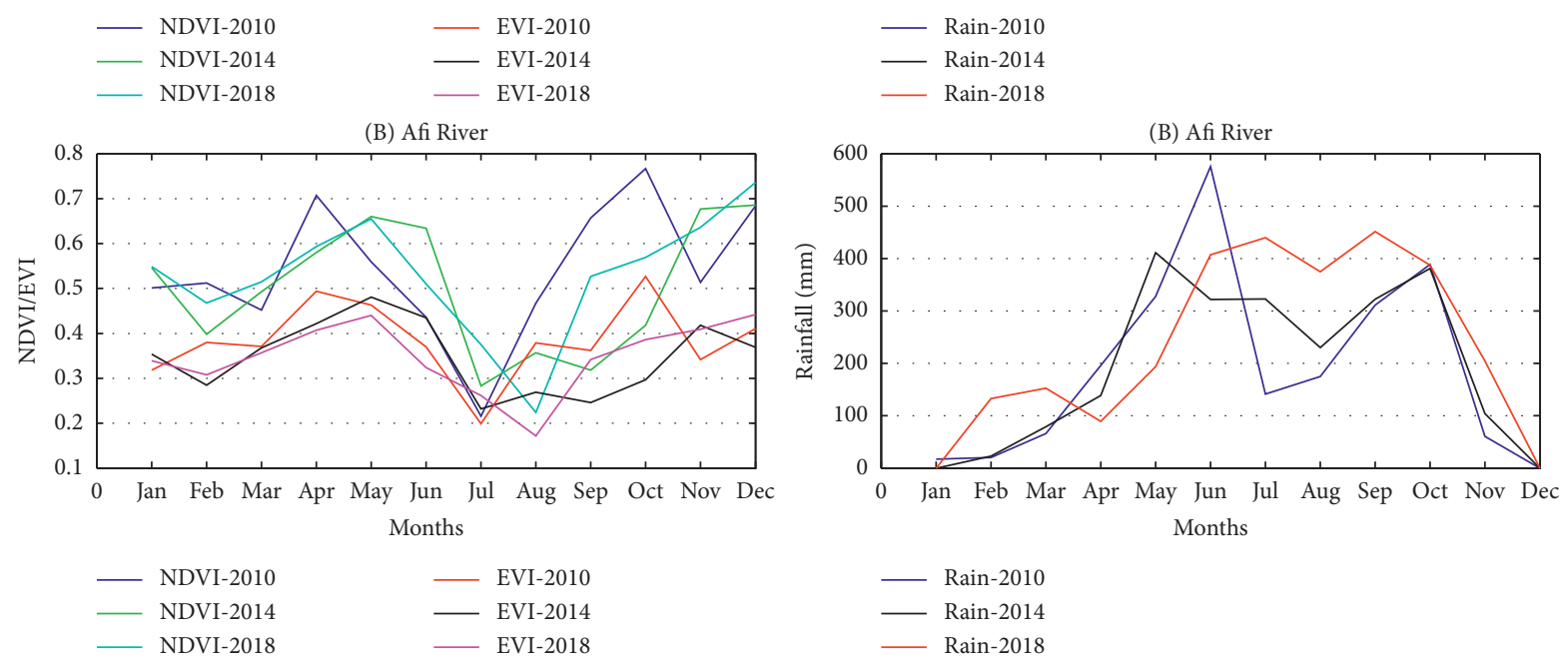

(D) Yache
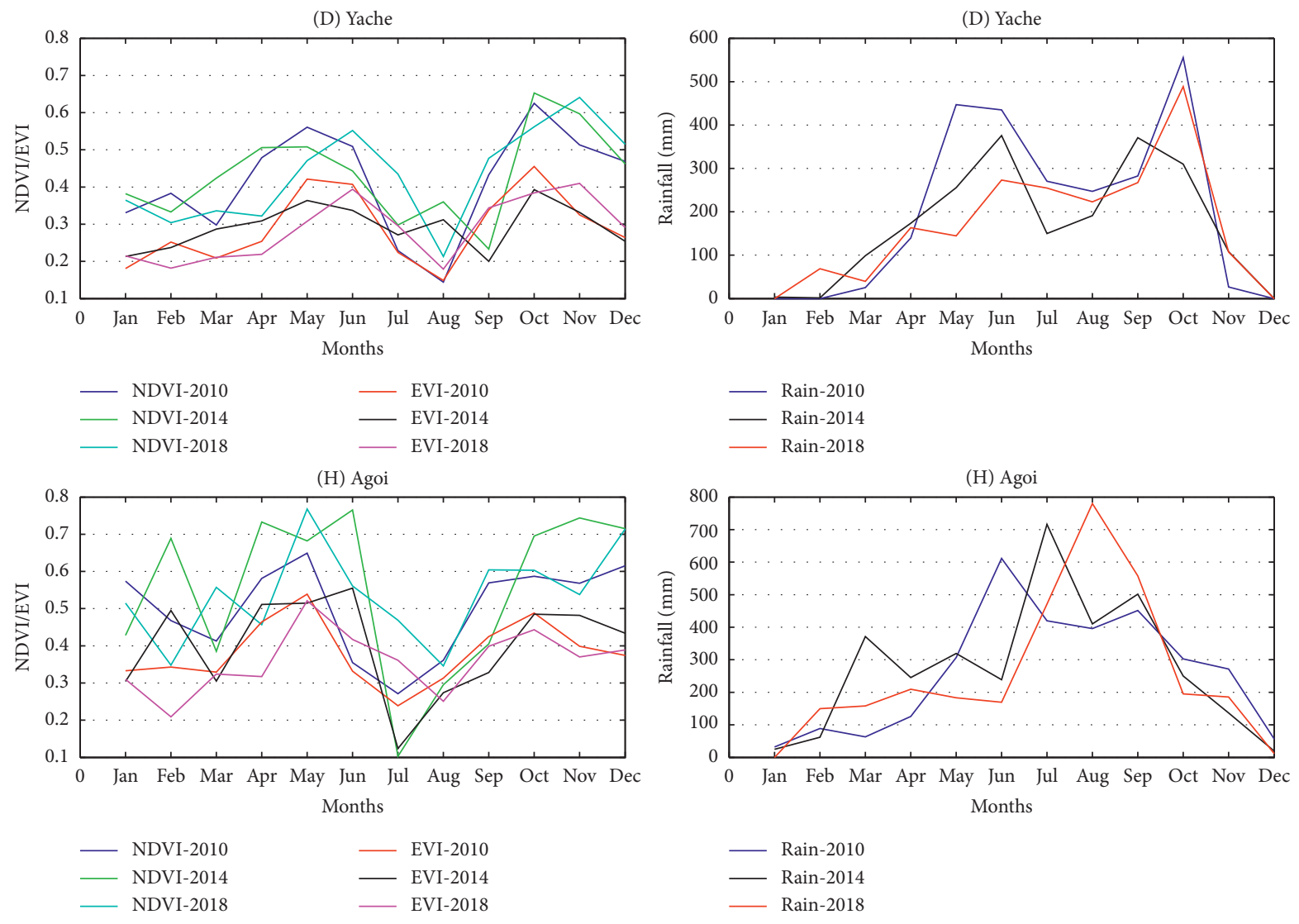

Rain-2010
$-\quad$ Rain-2014
Rain-2018

Figure 3: Continued. 

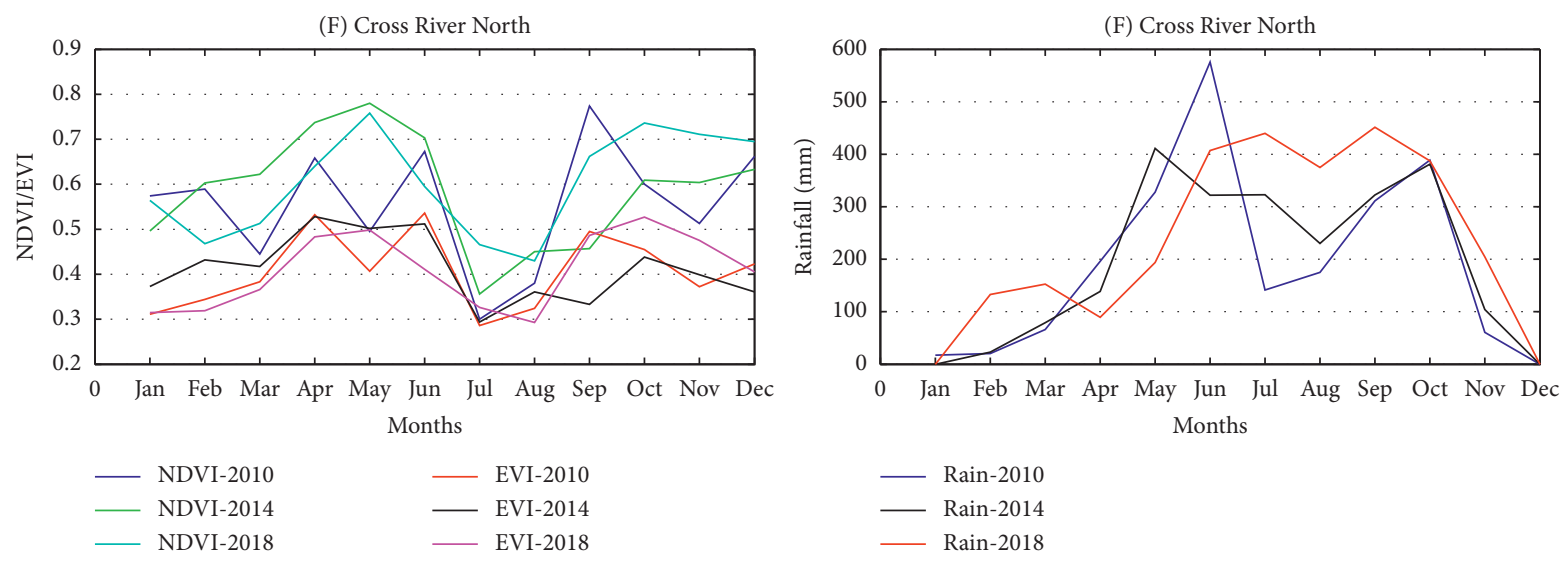

(G) Cross River South
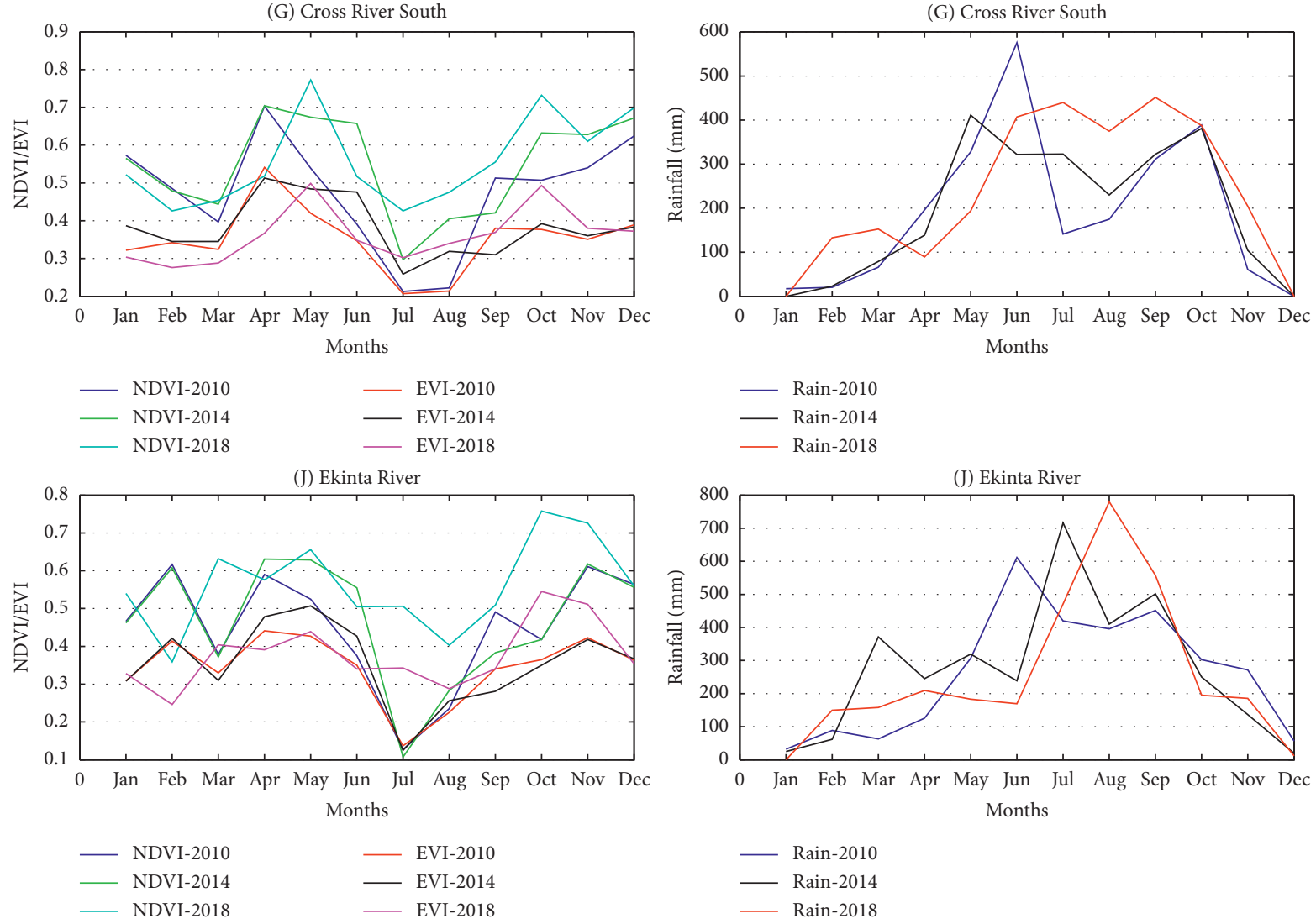

(E) Gabu
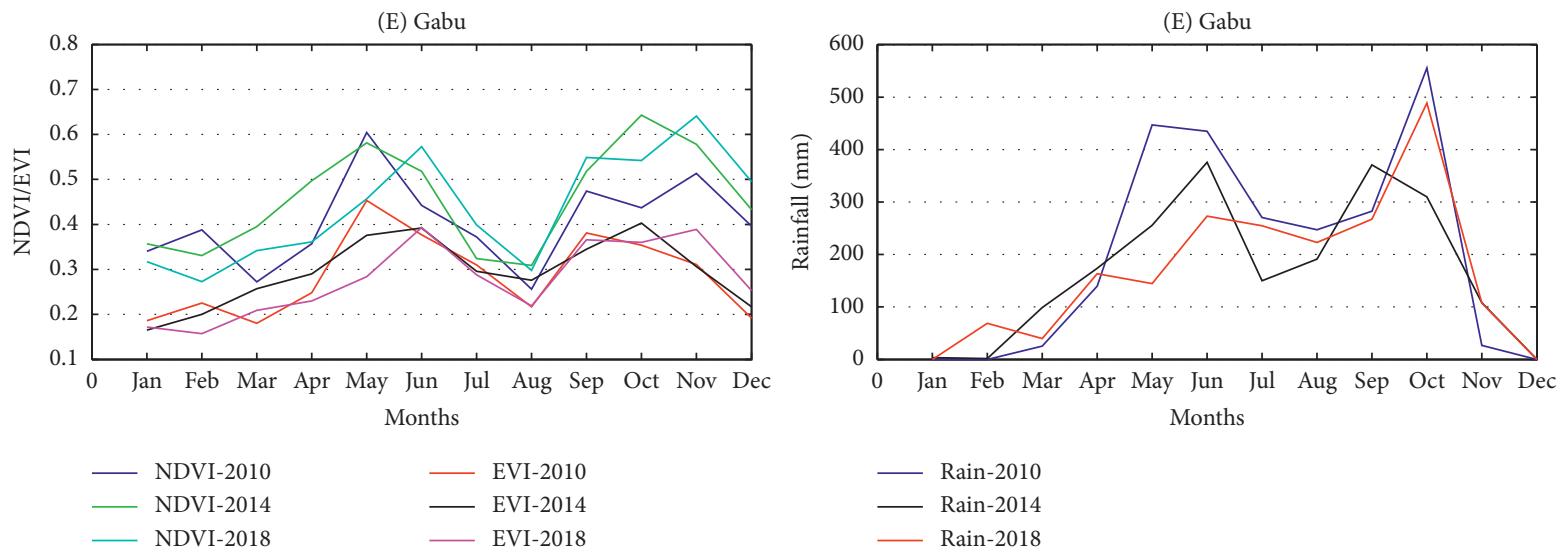

Figure 3: Continued. 

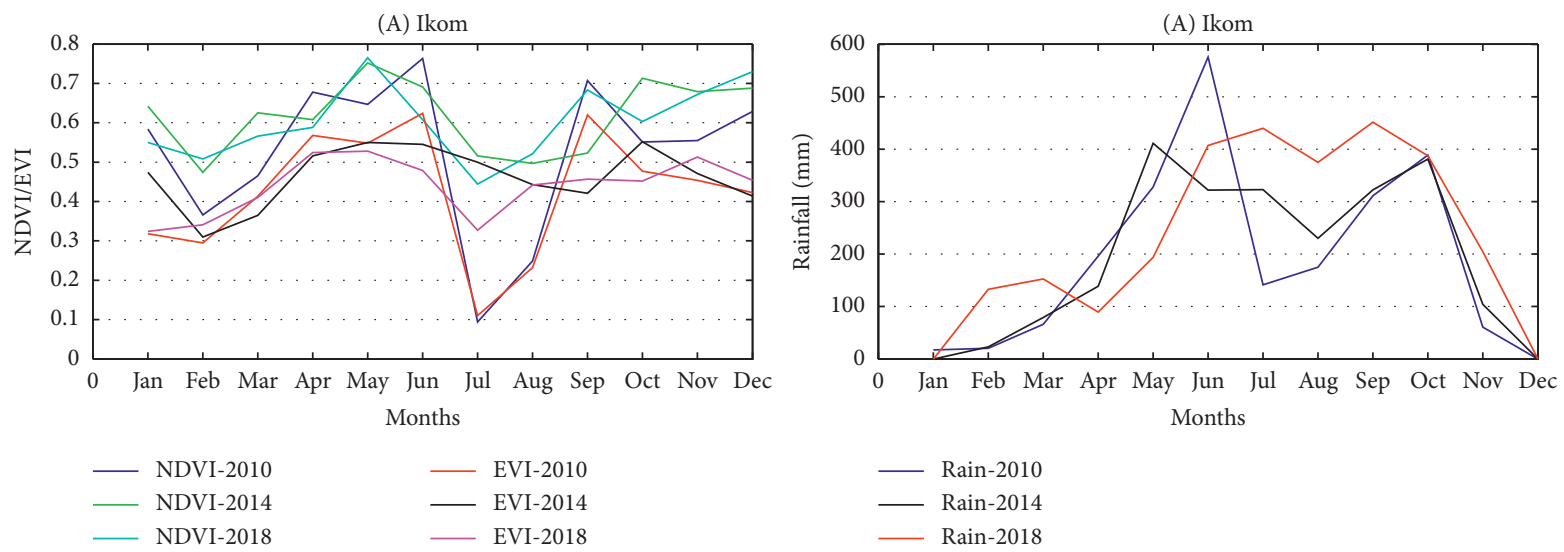

(C) Ikrigon
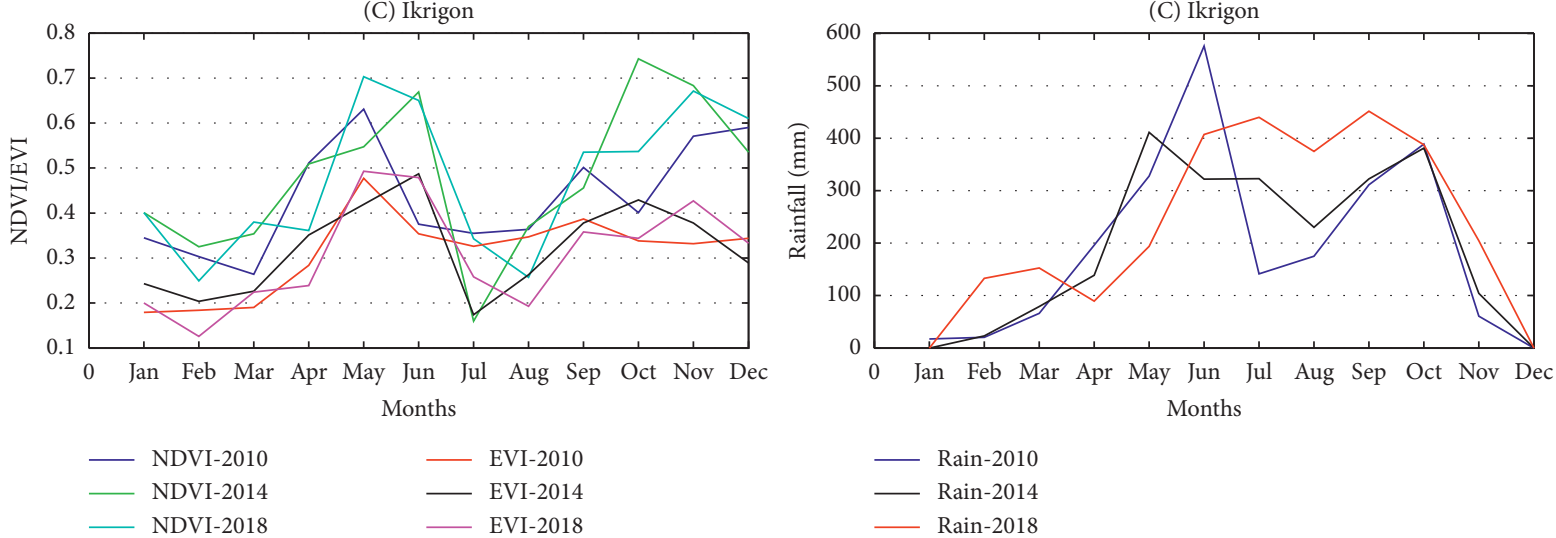

(N) Lower Enyong

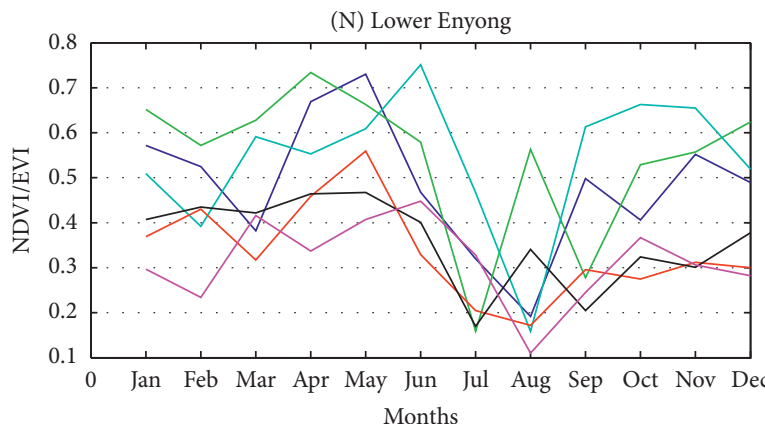

— Rain-2014

_ Rain-2018

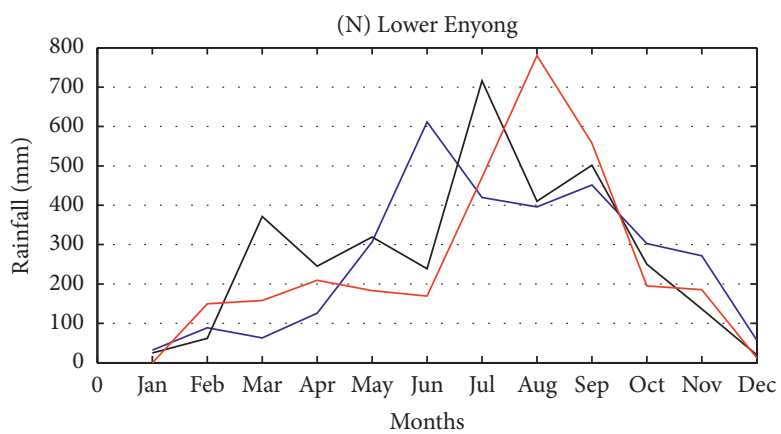

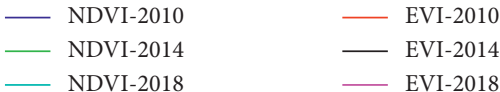

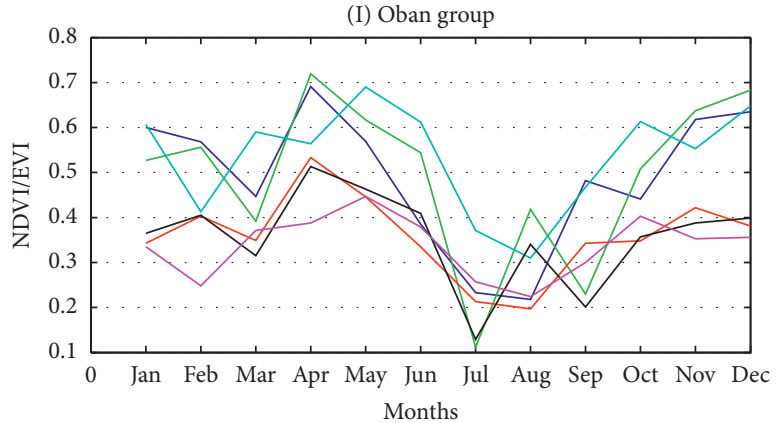

— Rain-2014

— Rain-2018

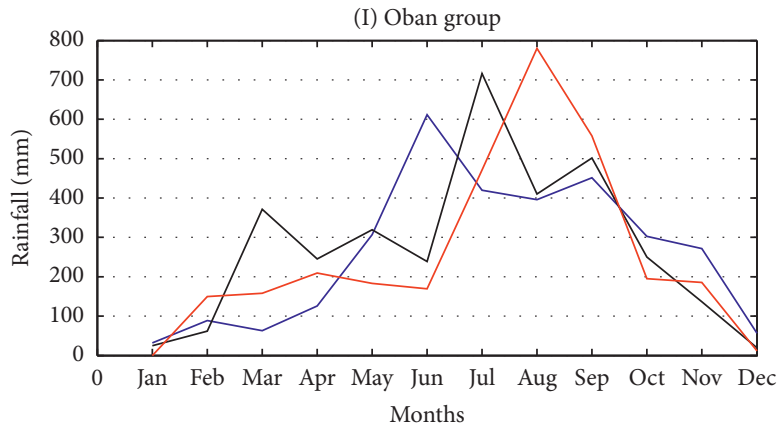

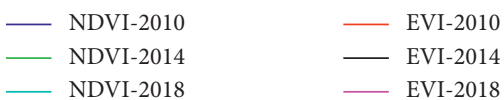

_ Rain-2010
Rain-2014
r

Figure 3: Continued. 

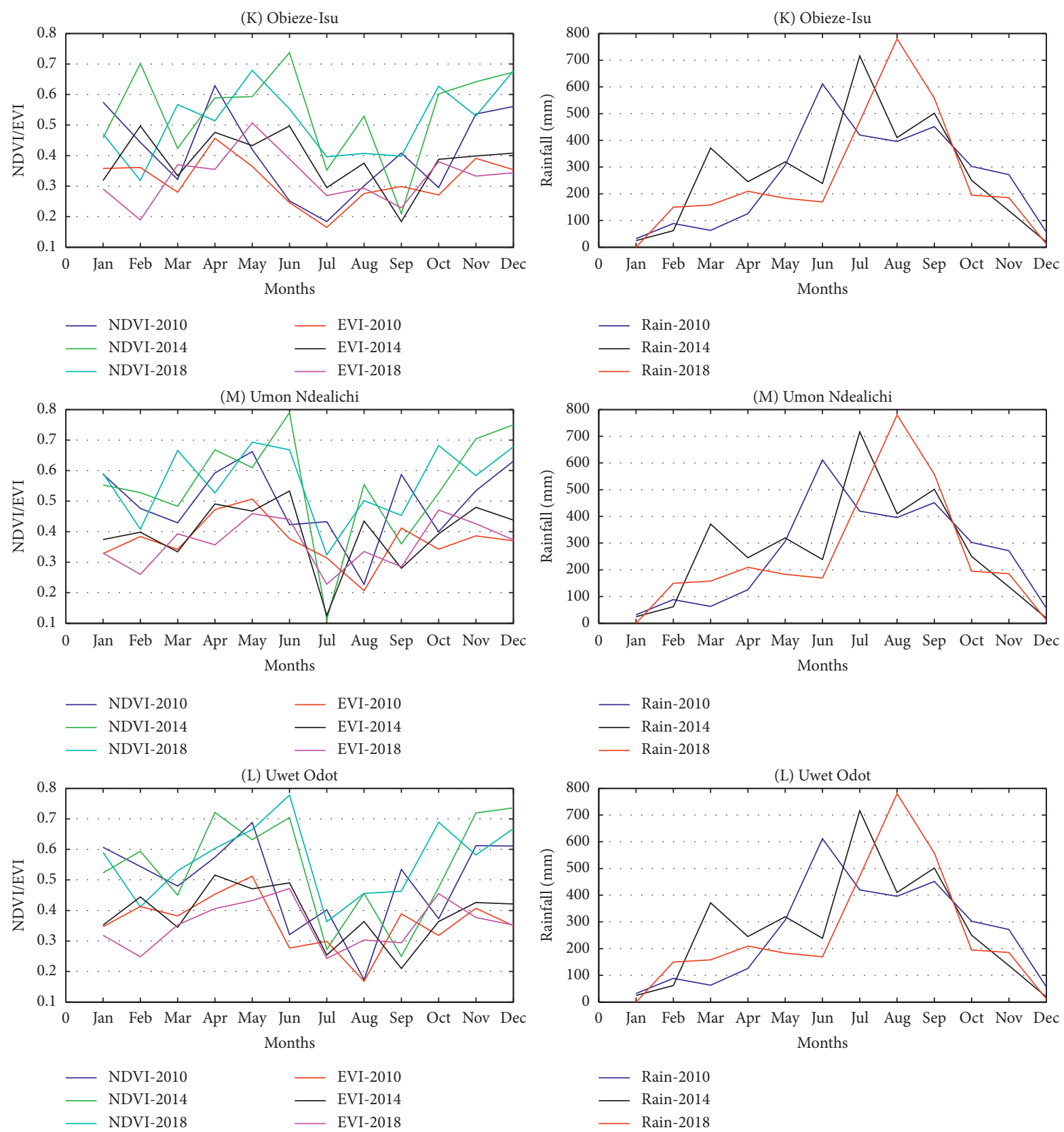

FIGURE 3: Monthly rainfall, NDVI, and EVI data for each of the three years.

sensitivity of NDVI to soil background and atmospheric effects) was observed between the values within the period of 2014-2018 and 2010-2018. The greening of the forest reserves (except Afi River) increased within 2010-2014 showing an improvement in their health conditions. Within 2014-2018, most of the forest reserves (except Afi River and Ekinta River) deteriorated in health, and many of them (except Cross River North, Cross River South, Ekinta River, Ikom, and Obieze-Isu) also deteriorated in health between 2010 and 2018 depicting negative changes in their percentages.

Generally, in Table 3, NDVI and EVI values of each of the forest reserves have high positive correlation coefficients as expected and confirmed in other studies. There is a general negative correlation between monthly rainfall data and the vegetation indices (NDVI and EVI) indicating that an increase in monthly rainfall does not directly increase the value of the NDVI in that particular month [27, 30-32]. The lower correlation coefficients between monthly NDVI and rainfall observed in this study were earlier confirmed by Herrmann et al. [23] who stated that "areas within the semiarid zone where moisture availability is more a function of exogenous stream flow, such as the Niger Delta, stand out of the zonal pattern by their lower correlation coefficients."

At this juncture, we have to point out that the limitations of this study are majorly lack of terrestrially acquired forest 

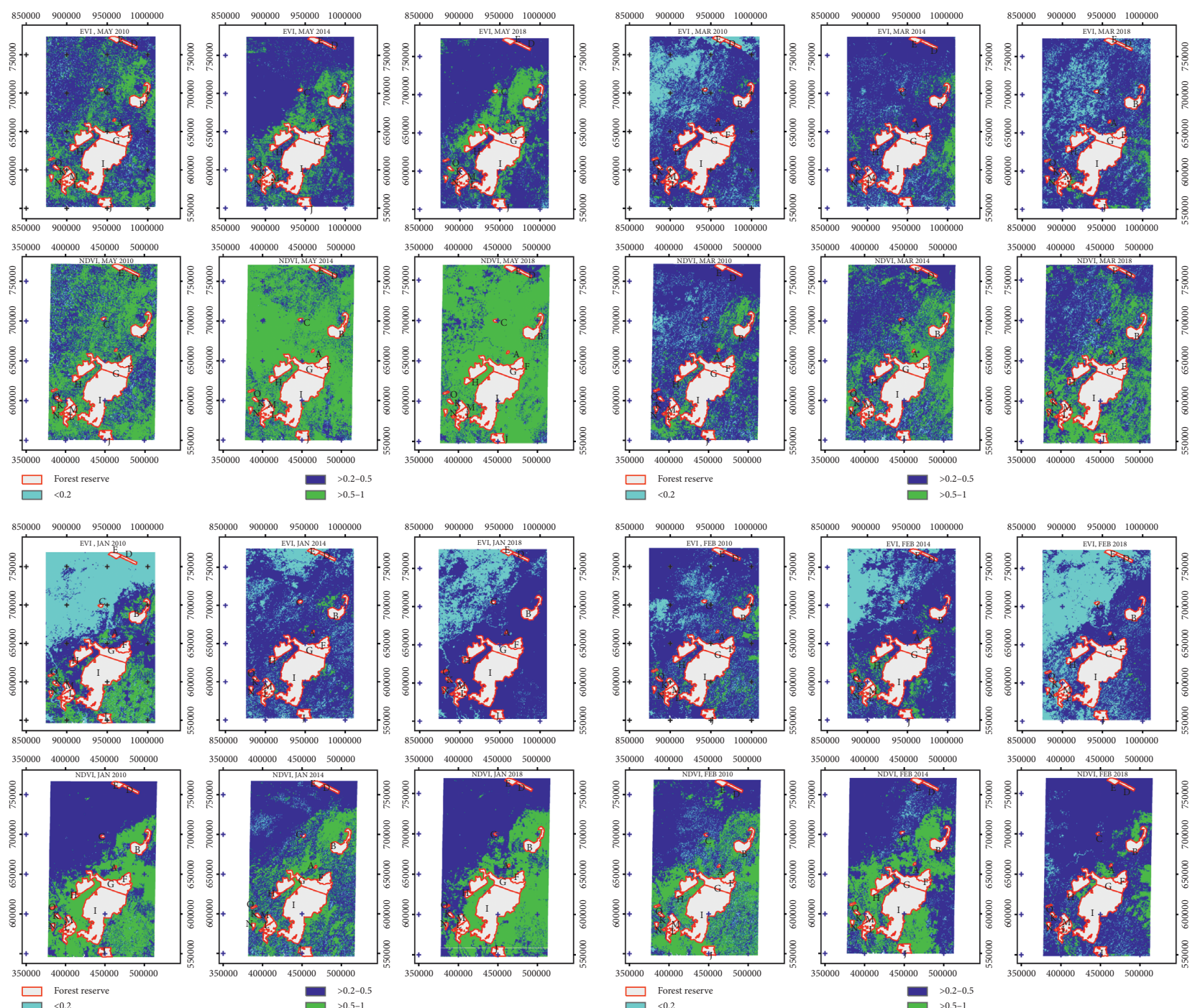

$$
\square<0.2
$$

ㄴ. $>0.2-0.1$
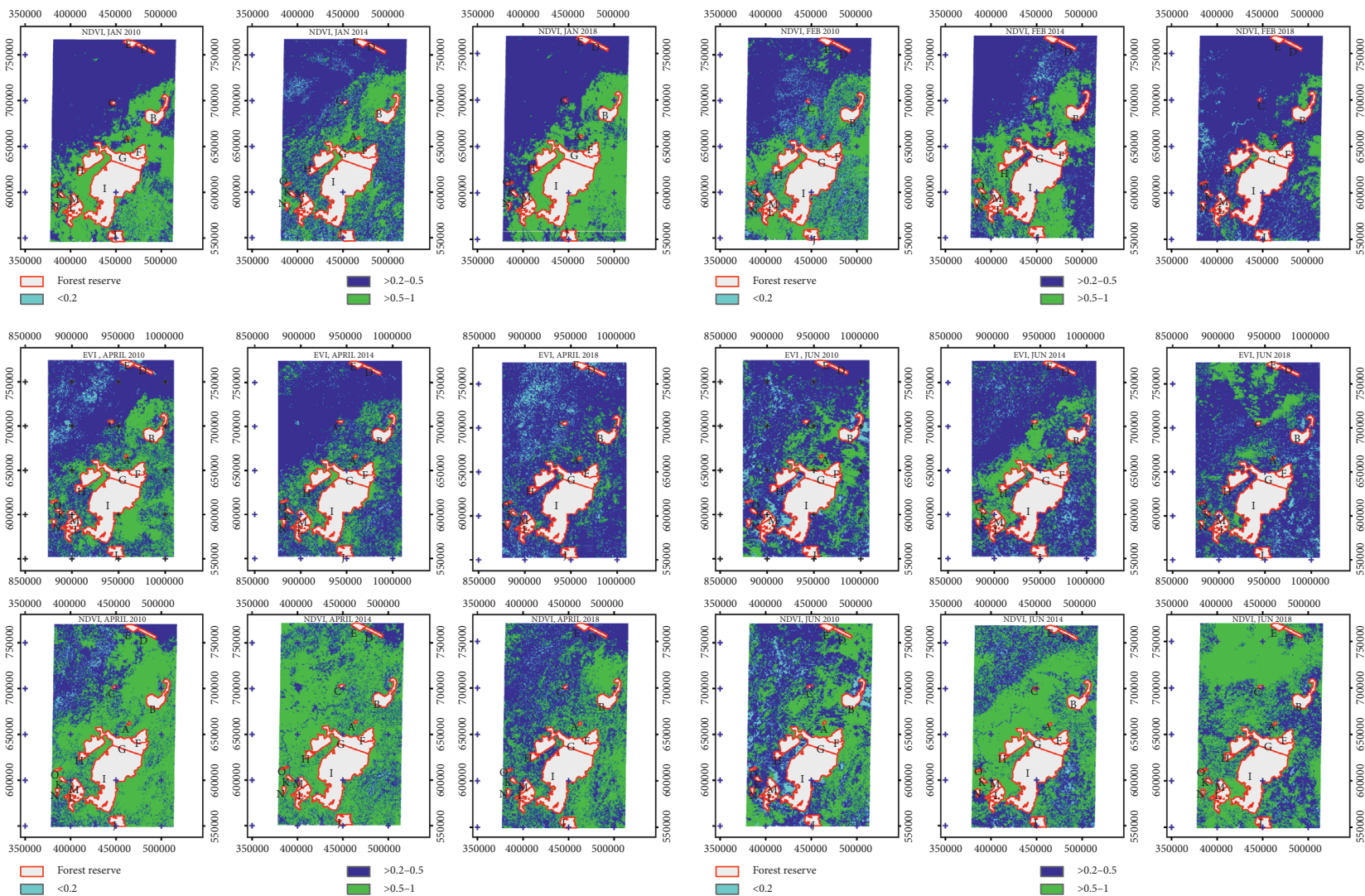

$\square$ For

뭉.5.
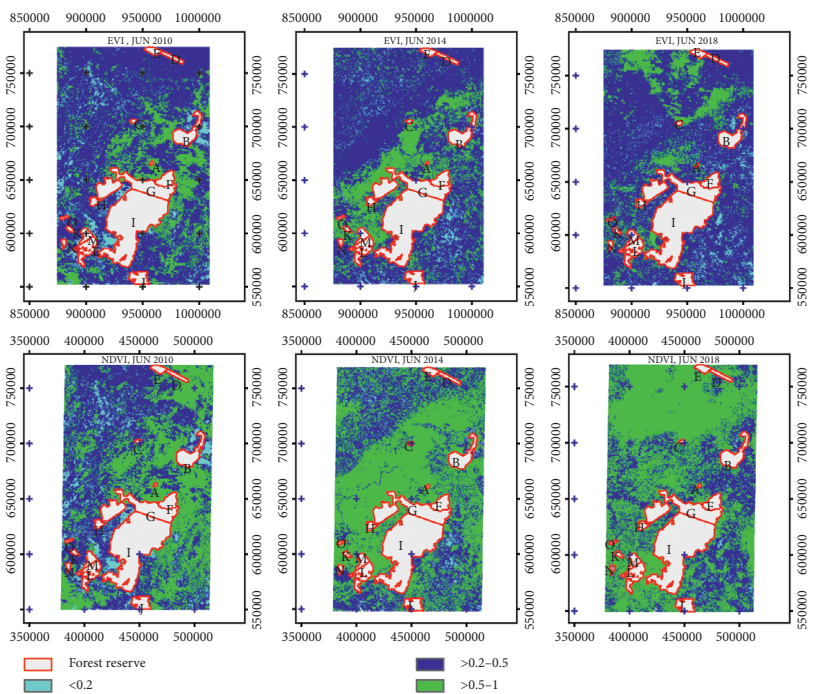

Figure 4: Continued. 

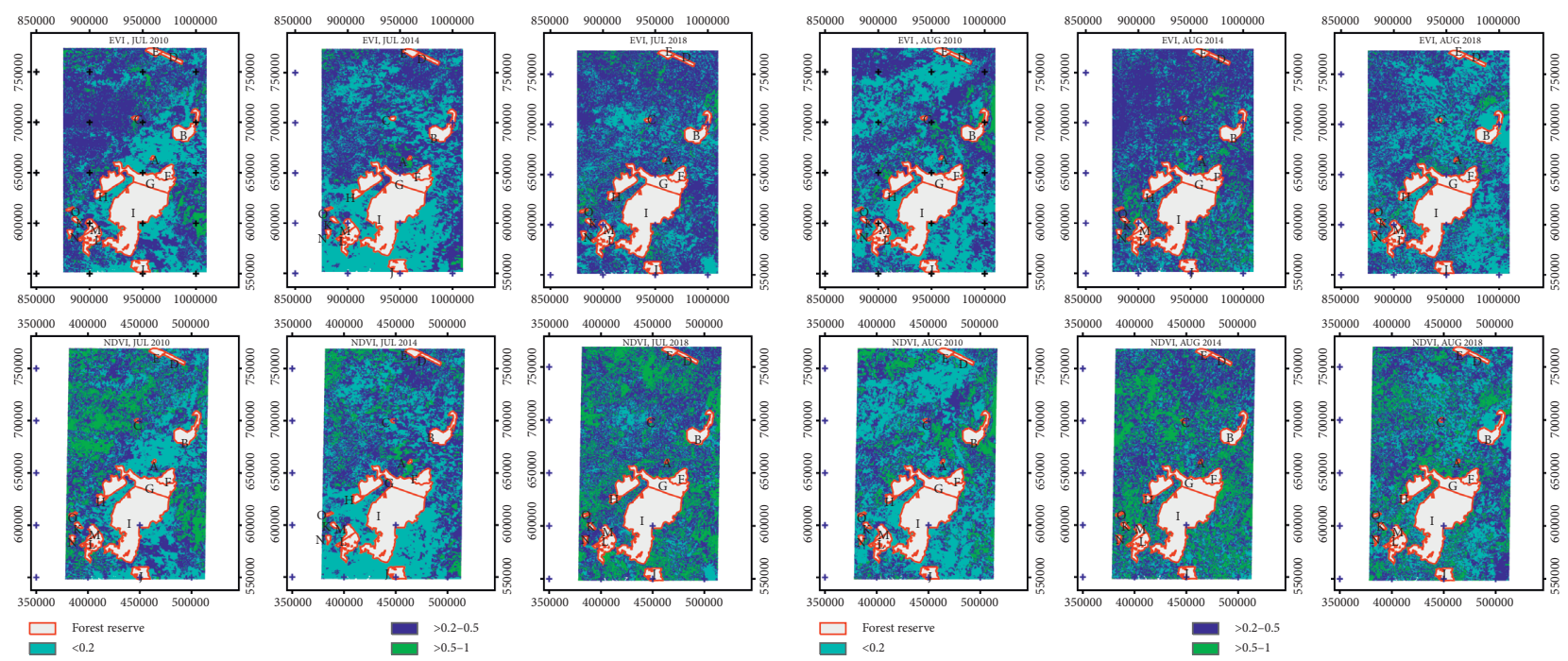

$\begin{array}{cccc}850000 & 900000 & 950000 & 1000000 \\ 350000 & 400000 & 450000 & 500000\end{array}$

-
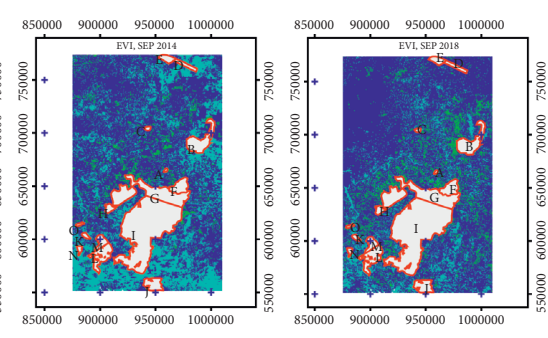

믐 ${ }^{\text {Fore }} 0.2$

드 $>0.2-0.5$
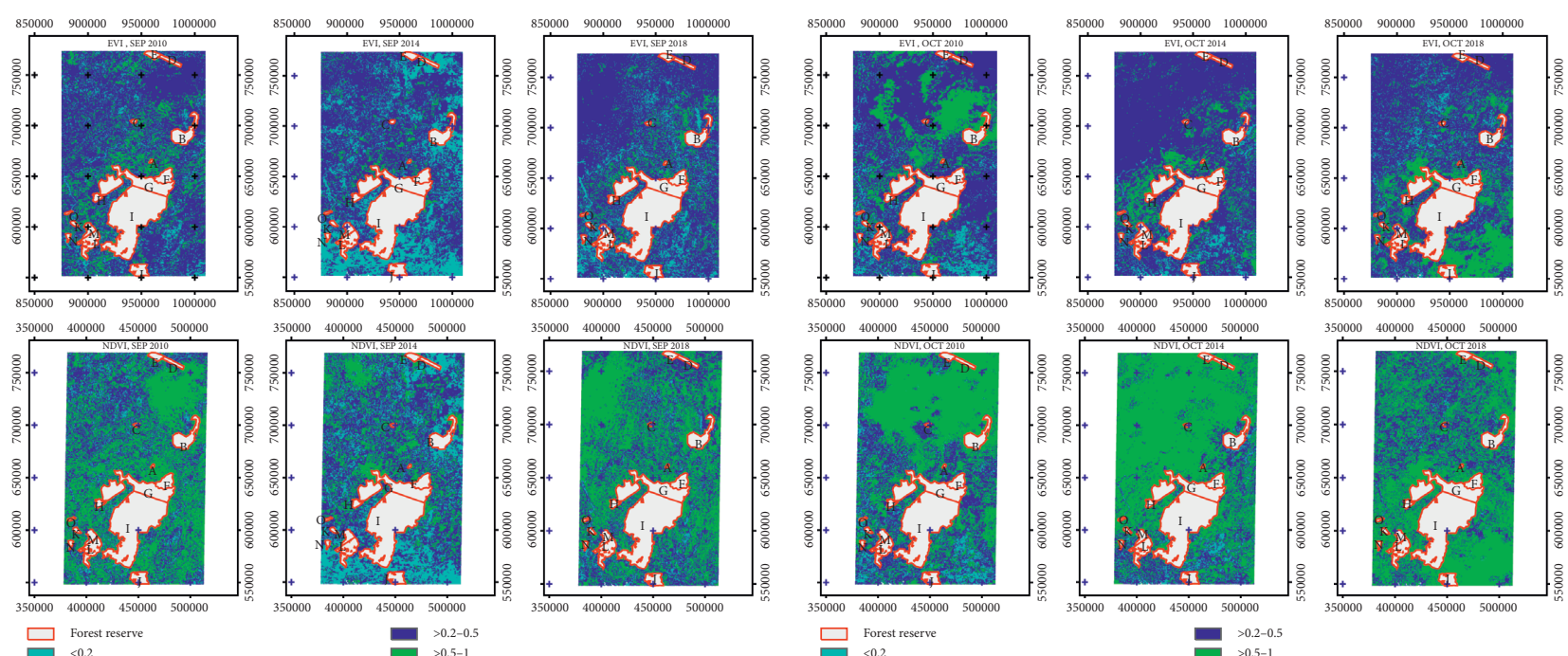

$$
\square \begin{aligned}
& \text { Forest r } \\
& <0.2
\end{aligned}
$$
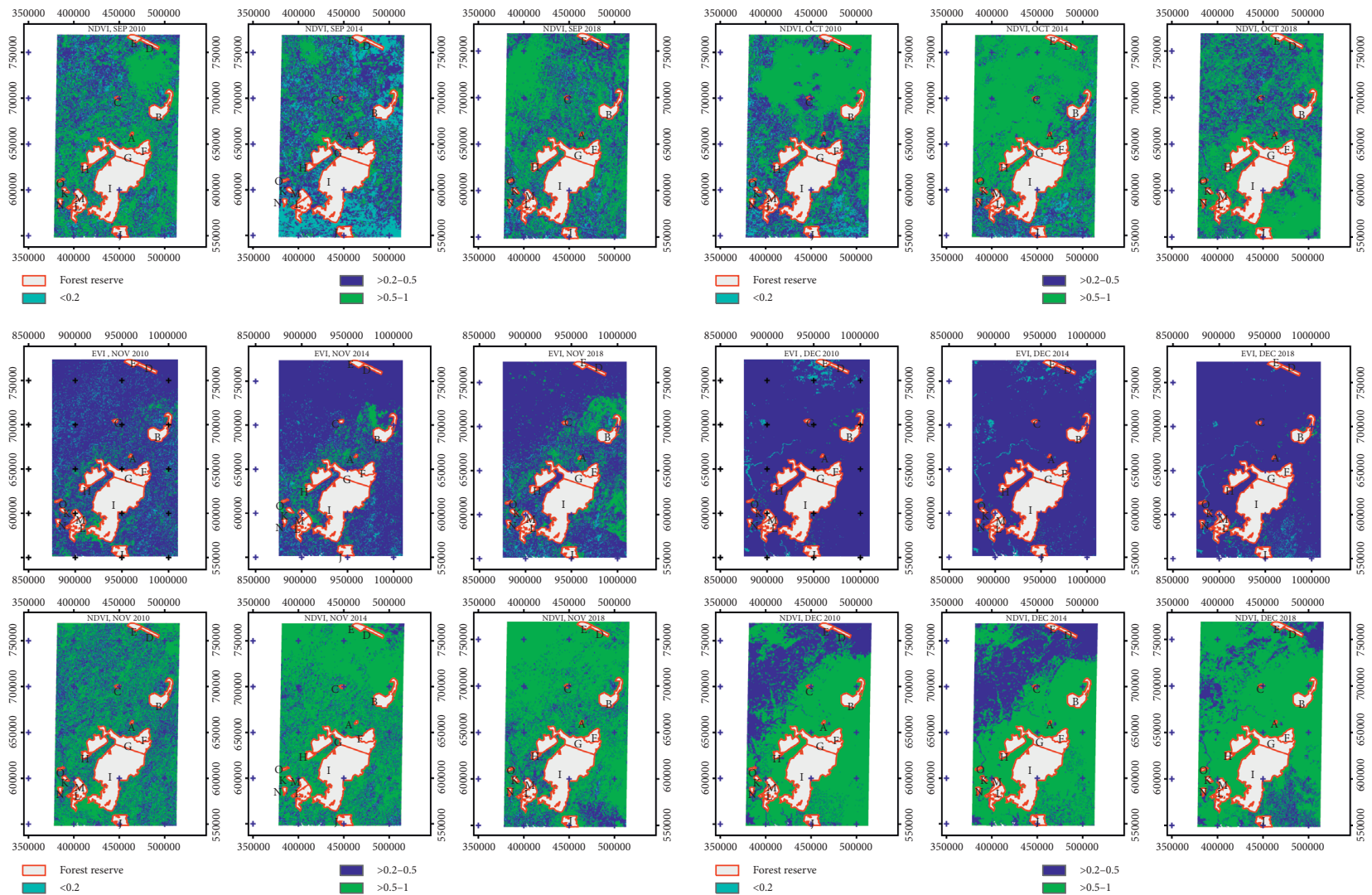

FIgUre 4: Monthly NDVI and EVI thematic output maps for each of the three years. 
TABLE 1: Yearly seasonal variation of vegetation indices.

\begin{tabular}{lcccccccccc}
\hline \multirow{2}{*}{ Season } & Year & \multicolumn{3}{c}{ Minimum } & \multicolumn{3}{c}{ Maximum } & & \multicolumn{2}{c}{ Mean } \\
& & NDVI & EVI & Rainfall & NDVI & EVI & Rainfall & NDVI & EVI & Rainfall \\
\hline \multirow{3}{*}{ Winter } & 2010 & 0.303 & 0.179 & 0.000 & 0.684 & 0.437 & 89.000 & 0.529 & 0.33584 & 35.644 \\
& 2014 & 0.325 & 0.165 & 0.000 & 0.750 & 0.497 & 61.600 & 0.549 & 0.35602 & 21.602 \\
& 2018 & 0.249 & 0.126 & 0.000 & 0.736 & 0.454 & 149.600 & 0.508 & 0.29702 & 46.456 \\
\hline \multirow{3}{*}{ Spring } & 2010 & 0.264 & 0.180 & 25.500 & 0.741 & 0.568 & 446.800 & 0.528 & 0.410 & 180.864 \\
& 2014 & 0.354 & 0.226 & 79.300 & 0.780 & 0.550 & 411.200 & 0.585 & 0.419 & 259.751 \\
& 2018 & 0.322 & 0.209 & 39.500 & 0.772 & 0.528 & 209.200 & 0.562 & 0.377 & 161.740 \\
\hline \multirow{3}{*}{ Summer } & 2010 & 0.094 & 0.110 & 141.400 & 0.763 & 0.624 & 611.400 & 0.322 & 0.281 & 395.240 \\
& 2014 & 0.103 & 0.124 & 149.800 & 0.790 & 0.555 & 716.200 & 0.437 & 0.344 & 371.711 \\
& 2018 & 0.159 & 0.110 & 169.300 & 0.778 & 0.479 & 780.200 & 0.465 & 0.327 & 421.656 \\
\hline \multirow{3}{*}{ Autumn } & 2010 & 0.295 & 0.271 & 26.600 & 0.774 & 0.620 & 555.200 & 0.530 & 0.386 & 305.247 \\
& 2014 & 0.210 & 0.184 & 104.400 & 0.744 & 0.552 & 501.500 & 0.534 & 0.362 & 282.807 \\
& 2018 & 0.398 & 0.229 & 107.200 & 0.758 & 0.545 & 557.600 & 0.601 & 0.395 & 321.033 \\
\hline
\end{tabular}

TABLE 2: Yearly rainfall data and vegetation indices.

\begin{tabular}{|c|c|c|c|c|c|c|c|c|c|}
\hline \multirow{2}{*}{ Forest reserves } & \multicolumn{3}{|c|}{ Rainfall } & \multicolumn{3}{|c|}{ NDVI } & \multicolumn{3}{|c|}{ EVI } \\
\hline & 2010 & 2014 & 2018 & 2010 & 2014 & 2018 & 2010 & 2014 & 2018 \\
\hline Afi River & 190.08 & 194.65 & 236.12 & 0.539 & 0.504 & 0.53 & 0.385 & 0.348 & 0.349 \\
\hline Achara Ihe & 260.43 & 274.58 & 255.85 & 0.485 & 0.566 & 0.548 & 0.38 & 0.4 & 0.37 \\
\hline Agoi & 260.43 & 274.58 & 255.85 & 0.501 & 0.553 & 0.54 & 0.382 & 0.401 & 0.359 \\
\hline Cross River North & 190.08 & 194.65 & 236.12 & 0.555 & 0.587 & 0.603 & 0.406 & 0.412 & 0.409 \\
\hline Cross River South & 190.08 & 194.65 & 236.12 & 0.476 & 0.548 & 0.559 & 0.351 & 0.381 & 0.362 \\
\hline Ekinta River & 260.43 & 274.58 & 255.85 & 0.45 & 0.469 & 0.561 & 0.344 & 0.354 & 0.377 \\
\hline Gabu & 202.43 & 169.83 & 169.22 & 0.404 & 0.457 & 0.437 & 0.286 & 0.294 & 0.277 \\
\hline Ikom & 190.08 & 194.65 & 236.12 & 0.524 & 0.618 & 0.603 & 0.423 & 0.464 & 0.438 \\
\hline Ikrigon & 190.08 & 194.65 & 236.12 & 0.434 & 0.479 & 0.475 & 0.312 & 0.32 & 0.306 \\
\hline Lower Enyong & 260.43 & 274.58 & 255.85 & 0.484 & 0.545 & 0.54 & 0.335 & 0.359 & 0.315 \\
\hline Oban group & 260.43 & 274.58 & 255.85 & 0.491 & 0.495 & 0.537 & 0.359 & 0.357 & 0.338 \\
\hline Obieze-Isu & 260.43 & 274.58 & 255.85 & 0.41 & 0.543 & 0.512 & 0.318 & 0.384 & 0.329 \\
\hline Umon Ndealichi & 260.43 & 274.58 & 255.85 & 0.499 & 0.553 & 0.565 & 0.37 & 0.396 & 0.363 \\
\hline Uwet Odot & 260.43 & 274.58 & 255.85 & 0.493 & 0.544 & 0.567 & 0.36 & 0.388 & 0.355 \\
\hline Yache & 202.43 & 169.83 & 169.22 & 0.415 & 0.433 & 0.433 & 0.29 & 0.293 & 0.286 \\
\hline
\end{tabular}

TABLE 3: Correlation coefficients for monthly data.

\begin{tabular}{|c|c|c|c|c|c|c|c|c|c|}
\hline \multirow{2}{*}{ Forest reserves } & \multicolumn{3}{|c|}{ Corel_RF_NDVI } & \multicolumn{3}{|c|}{ Corel_RF_EVI } & \multicolumn{3}{|c|}{ Corel_NDVI_EVI } \\
\hline & 2010 & 2014 & 2018 & 2010 & 2014 & 2018 & 2010 & 2014 & 2018 \\
\hline Ikom & 0.416 & 0.172 & -0.211 & 0.589 & 0.661 & 0.059 & 0.931 & 0.598 & 0.729 \\
\hline Afi River & 0.13 & -0.27 & -0.546 & 0.326 & -0.056 & -0.503 & 0.854 & 0.921 & 0.98 \\
\hline Ikrigon & 0.096 & 0.228 & 0.043 & 0.585 & 0.555 & 0.289 & 0.719 & 0.883 & 0.948 \\
\hline Yache & 0.386 & 0.061 & 0.285 & 0.715 & 0.435 & 0.508 & 0.881 & 0.799 & 0.954 \\
\hline Gabu & 0.421 & 0.584 & 0.391 & 0.801 & 0.914 & 0.619 & 0.833 & 0.752 & 0.941 \\
\hline Cross River North & 0.294 & 0.007 & -0.127 & 0.658 & 0.148 & 0.136 & 0.769 & 0.909 & 0.902 \\
\hline Cross River South & -0.139 & -0.072 & -0.122 & 0.171 & 0.101 & 0.171 & 0.89 & 0.876 & 0.911 \\
\hline Agoi & -0.436 & -0.72 & -0.414 & -0.062 & -0.625 & -0.189 & 0.823 & 0.976 & 0.885 \\
\hline Oban group & -0.633 & -0.827 & -0.79 & -0.433 & -0.715 & -0.609 & 0.903 & 0.954 & 0.933 \\
\hline Ekinta River & -0.493 & -0.764 & -0.388 & -0.33 & -0.616 & -0.261 & 0.926 & 0.958 & 0.975 \\
\hline Obieze-Isu & -0.665 & -0.677 & -0.519 & -0.581 & -0.534 & -0.322 & 0.929 & 0.936 & 0.874 \\
\hline Uwet Odot & -0.559 & -0.755 & -0.568 & -0.405 & -0.603 & -0.382 & 0.889 & 0.927 & 0.923 \\
\hline Lower Enyong & -0.306 & -0.738 & -0.538 & -0.338 & -0.635 & -0.581 & 0.912 & 0.931 & 0.832 \\
\hline Achara Ihe & -0.404 & -0.604 & -0.093 & -0.29 & -0.47 & 0.16 & 0.94 & 0.95 & 0.85 \\
\hline Umon Ndealichi & -0.373 & -0.763 & -0.551 & -0.103 & -0.669 & -0.389 & 0.808 & 0.96 & 0.909 \\
\hline
\end{tabular}


TABLE 4: Percentage change of vegetation indices.

\begin{tabular}{|c|c|c|c|c|c|c|}
\hline \multirow{2}{*}{ Forest reserves } & \multicolumn{3}{|c|}{ NDVI (\% change) } & \multicolumn{3}{|c|}{ EVI (\% change) } \\
\hline & 2010-2014 & 2014-2018 & 2010-2018 & 2010-2014 & $2014-2018$ & 2010-2018 \\
\hline Afi River & -6.49 & 5.16 & -2.34 & -9.61 & 0.29 & -9.35 \\
\hline Achara Ihe & 16.70 & -3.18 & 16.58 & 5.26 & -7.50 & -2.63 \\
\hline Agoi & 10.38 & -2.35 & 10.21 & 4.97 & -10.47 & -6.02 \\
\hline Cross River North & 5.77 & 2.73 & 11.82 & 1.48 & -0.73 & 0.74 \\
\hline Cross River South & 15.13 & 2.01 & 23.65 & 8.55 & -4.99 & 3.13 \\
\hline Ekinta River & 4.22 & 19.62 & 32.27 & 2.91 & 6.50 & 9.59 \\
\hline Gabu & 13.12 & -4.38 & 11.54 & 2.80 & -5.78 & -3.15 \\
\hline Ikom & 17.94 & -2.43 & 18.68 & 9.69 & -5.60 & 3.55 \\
\hline Ikrigon & 10.37 & -0.84 & 13.14 & 2.56 & -4.38 & -1.92 \\
\hline Lower Enyong & 12.60 & -0.92 & 16.72 & 7.16 & -12.26 & -5.97 \\
\hline Oban group & 0.81 & 8.48 & 12.81 & -0.56 & -5.32 & -5.85 \\
\hline Obieze-Isu & 32.44 & -5.71 & 32.08 & 20.75 & -14.32 & 3.46 \\
\hline Umon Ndealichi & 10.82 & 2.17 & 17.84 & 7.03 & -8.33 & -1.89 \\
\hline Uwet Odot & 10.34 & 4.23 & 20.56 & 7.78 & -8.51 & -1.39 \\
\hline Yache & 4.34 & 0.00 & 6.21 & 1.03 & -2.39 & -1.38 \\
\hline
\end{tabular}

inventory data and unavailability of long-standing and standardized forest health inventory programs that could have further validated the obtained results, but the obtained results corroborated the findings of these studies $[1,3,4]$ which show that some of the forest reserves are greatly stressed.

\section{Conclusion}

Due to several underlying factors that determine vegetation health, assessing forest health is a complex process. However, in this study, we assessed the health of fifteen forest reserves in Cross River State, Nigeria, using the meteorological data and MOD13A1-derived Normalized Difference Vegetation Index (NDVI) and Enhanced Vegetation Index (EVI) for the years 2010, 2014, and 2018. Monthly mean values of the vegetation indices (NDVI and EVI) were estimated for each of the forest reserves. The relationship between the vegetation indices and rainfall data was analyzed by computing correlation coefficients. To assess the health of each of the fifteen forest reserves, percentage change between the estimated mean values of the vegetation indices and seasonal variation of vegetation indices was determined on yearly basis for the period of study.

The computed monthly mean values of NDVI and EVI range from $\mathbf{0 . 0 9 4}$ to $\mathbf{0 . 7 9 0}$ and from $\mathbf{0 . 1 1}$ to $\mathbf{0 . 6 2 4}$, respectively, while rainfall data range from $\mathbf{0}$ to $780.2 \mathrm{~mm} / \mathrm{month}$ within the period of study. The computed yearly mean values of NDVI and EVI range from 0.404 to 0.618 and from 0.277 to $\mathbf{0 . 4 6 4}$, respectively, while rainfall data range from 169.22 to $274.58 \mathrm{~mm}$ / month within the period of study. Similarly, the correlation coefficients between monthly rainfall data and monthly mean values of NDVI and EVI varied from $\mathbf{- 0 . 8 2 7}$ to $\mathbf{0 . 5 8 4}$ and $\mathbf{- 0 . 7 1 5}$ to $\mathbf{0 . 9 1 4}$. Equally, the relationship between NDVI and EVI ranges from $\mathbf{0 . 5 9 8}$ to 0.980. The obtained mean values of the vegetation indices, which are measures of the chlorophyll content of each of the fifteen forest reserves, indicate that some of the forest reserves are moderately healthy while some are greatly stressed. The greening of the forest reserves as shown in positive trends in NDVI indicates a net increase in biomass production during the period under study.

\section{Data Availability}

The MODIS data used to support the findings of the study are publicly available.

\section{Conflicts of Interest}

The authors declare that they have no conflicts of interest.

\section{Supplementary Materials}

Table S1 shows the seasonal variation of rainfall, NDVI, and EVI of year 2010 for the fifteen forest reserves under study. It is observed that there is a general increase in the mean values of vegetation indices as we move from Winter to Autumn, and this confirms that the more the rainfall during the preceding season the more the greenness of vegetation during the following season. Table S2 shows the seasonal variation of rainfall, NDVI, and EVI of year 2014 for the fifteen forest reserves under study. It is observed that there is a general increase in the mean values of vegetation indices as we move from Winter to Autumn, and this confirms that the more the rainfall during the preceding season the more the greenness of vegetation during the following season. Table S3 shows the seasonal variation of rainfall, NDVI, and EVI of year 2018 for the fifteen forest reserves under study. It is observed that there is a general increase in the mean values of vegetation indices as we move from Winter to Autumn, and this confirms that the more the rainfall during the preceding season the more the greenness of vegetation during the following season. (Supplementary Materials) 


\section{References}

[1] O. O. O. Enuoh and F. E. Bisong, "Colonial forest policies and tropical deforestation: the case of Cross River State, Nigeria," Open Journal of Forestry, vol. 5, no. 1, pp. 66-79, 2015.

[2] J. O'Laughlin, R. Livingston, R. Their, J. Thornton, D. E. Toweill, and E. Morelan, "Defining and measuring forest health," Journal of Sustainable Forestry, vol. 2, no. 1-2, pp. 65-85, 1994.

[3] UN-REDD Programme, Study on the Drivers of Deforestation and Forest Degradation in Cross River State: A collaboration between the National Space Research and Development Agency and FAO, UN-REDD Programme, Geneva, Switzerland, 2015.

[4] UN-REDD Programme, Natural Resources and Sustainable Forest Management: Towards a REDD+ Strategy for Cross River State, V. N. Muthui and S. O. Adedoyin, Eds., Part of the Series of Reports Prepared for the REDD+ Strategy, UNREDD Programme, Geneva, Switzerland, 2016.

[5] M. Immitzer, C. Stepper, S. Böck, C. Straub, and C. Atzberger, "Use of WorldView-2 stereo imagery and National Forest Inventory data for wall-to-wall mapping of growing stock," Forest Ecology and Management, vol. 359, pp. 232-246, 2016.

[6] A. Massey, D. Mandallaz, and A. Lanz, "Integrating remote sensing and past inventory data under the new annual design of the Swiss National Forest Inventory using three-phase design-based regression estimation," Canadian Journal of Forest Research, vol. 44, no. 10, pp. 1177-1186, 2014.

[7] R. McRoberts and E. Tomppo, "Remote sensing support for national forest inventories," Remote Sensing of Environment, vol. 110, no. 4, pp. 412-419, 2007.

[8] S. Sarmah, G. Jia, A. Zhang, and M. Singha, "Assessing seasonal trends and variability of vegetation growth from NDVI3g, MODIS NDVI and EVI over South Asia," Remote Sensing Letters, vol. 9, no. 12, pp. 1195-1204, 2018.

[9] C. Jeganathan and N. Nishant, "Scrutinising MODIS and GIMMS vegetation indices for extracting growth rhythm of natural vegetation in India," Journal of the Indian Society of Remote Sensing, vol. 42, no. 2, pp. 397-408, 2014.

[10] R. Ogaya, A. Barbeta, C. Başnou, and J. Peñuelas, "Satellite data as indicators of tree biomass growth and forest dieback in a Mediterranean holm oak forest," Annals of Forest Science, vol. 72, no. 1, pp. 135-144, 2015.

[11] P. Cristiano, N. Madanes, P. Campanello et al., "High NDVI and potential canopy photosynthesis of South American subtropical forests despite seasonal changes in leaf area index and air temperature," Forests, vol. 5, no. 2, pp. 287-308, 2014.

[12] F. Kovács, "NDVI/EVI monitoring in forest areas to assessment the climate change effects in Hungarian Great Plain from 2000," in Proceedings of the Remote Sensing for Agriculture, Ecosystems, and Hydrology XX, vol. 10783, p. $107831 \mathrm{H}$, International Society for Optics and Photonics, Berlin, Germany, September 2018.

[13] N. Ya'acob, A. B. M. Azize, N. A. Mahmon, A. L. Yusof, N. F. Azmi, and N. Mustafa, "Temporal forest change detection and forest health assessment using Remote Sensing," IOP Conference Series: Earth and Environmental Science, vol. 19, no. 1, Article ID 012017, 2014.

[14] A. Kume, "Importance of the green color, absorption gradient, and spectral absorption of chloroplasts for the radiative energy balance of leaves," Journal of Plant Research, vol. 130, no. 3, pp. 501-514, 2017.

[15] L. Kouadio, N. Newlands, A. Davidson, Y. Zhang, and A. Chipanshi, "Assessing the performance of MODIS NDVI and EVI for seasonal crop yield forecasting at the ecodistrict scale," Remote Sensing, vol. 6, no. 10, pp. 10193-10214, 2014.

[16] P.-Y. Chen, G. Fedosejevs, M. Tiscareño-LóPez, and J. G. Arnold, "Assessment of MODIS-EVI, MODIS-NDVI and VEGETATION-NDVI composite data using agricultural measurements: an example at corn fields in Western Mexico," Environmental Monitoring and Assessment, vol. 119, no. 1-3, pp. 69-82, 2006.

[17] A. Gulácsi and F. Kovács, "Drought monitoring of forest vegetation using MODIS-based normalized difference drought index in Hungary," Hungarian Geographical Bulletin, vol. 67, no. 1, pp. 29-42, 2018.

[18] I. Barka, T. Bucha, T. Molnár, N. Móricz, Z. Somogyi, and M. Koreň, "Suitability of MODIS-based NDVI index for forest monitoring and its seasonal applications in Central Europe," Central European Forestry Journal, vol. 65, no. 3-4, pp. 206217, 2019.

[19] T. Hlásny, I. Barka, Z. Sitková, T. Bucha, M. Konôpka, and M. Lukáć, "MODIS-based vegetation index has sufficient sensitivity to indicate stand-level intra-seasonal climatic stress in oak and beech forests," Annals of Forest Science, vol. 72, no. 1, pp. 109-125, 2015.

[20] L. W. Ndungu, A. M. Oware, S. O. Otieno, A. M. Wahome, R. Mugo, and E. C. Adams, "Application of MODIS NDVI for monitoring Kenyan rangelands through a web based decision support tool," Frontiers in Environmental Science, vol. 7, p. 187, 2019.

[21] V. Bahamóndez, M. Stuven, M. Caroline, S. Müller-Using, Y. V. Rojas Ponce, and G. E. Vergara Asenjo, "Case studies on measuring and assessing forest degradation," An Operational Approach to Forest Degradation, 2009.

[22] J. Meng, S. Li, W. Wang, Q. Liu, S. Xie, and W. Ma, "Mapping forest health using spectral and textural information extracted from spot-5 satellite images," Remote Sensing, vol. 8, no. 9, p. $719,2016$.

[23] S. M. Herrmann, A. Anyamba, and C. J. Tucker, "Recent trends in vegetation dynamics in the African Sahel and their relationship to climate," Global Environmental Change, vol. 15, no. 4, pp. 394-404, 2005.

[24] A. Huete, C. Justice, and W. Van Leeuwen, MODIS Vegetation Index (MOD13) Algorithm Theoretical Basis Document, NASA Goddard Space Flight Centre, Greenbelt, MD, USA, 1999.

[25] K. Didan, A. B. Munoz, R. Solano, and A. Huete, MODIS Vegetation Index User's Guide (MOD13 Series), University of Arizona: Vegetation Index and Phenology Lab, Tucson, Arizona, 2015.

[26] V. K. Prasad, E. Anuradha, and K. V. S. Badarinath, "Climatic controls of vegetation vigor in four contrasting forest types of India-evaluation from national oceanic and atmospheric administration's advanced very high resolution radiometer datasets (1990-2000)," International Journal of Biometeorology, vol. 50, no. 1, pp. 6-16, 2005.

[27] W. Thavorntam and N. Tantemsapya, "Vegetation greenness modeling in response to climate change for Northeast Thailand," Journal of Geographical Sciences, vol. 23, no. 6, pp. 1052-1068, 2013.

[28] Food and Agriculture Organization of the United Nations, Global Forest Resources Assessment 2015. How Are the World's Forests Changing?, Food and Agriculture Organization, Rome, Italy, 2nd edition, 2016.

[29] B. Matsushita, W. Yang, J. Chen, Y. Onda, and G. Qiu, "Sensitivity of the enhanced vegetation index (EVI) and normalized difference vegetation index (NDVI) to 
topographic effects: a case study in high-density cypress forest," Sensors, vol. 7, no. 11, pp. 2636-2651, 2007.

[30] S. E. Nicholson, M. L. Davenport, and A. R. Malo, "A comparison of the vegetation response to rainfall in the Sahel and East Africa, using normalized difference vegetation index from NOAA AVHRR," Climatic Change, vol. 17, no. 2-3, pp. 209-241, 1990.

[31] A. Lotsch, M. A. Friedl, B. T. Anderson, and C. J. Tucker, "Coupled vegetation-precipitation variability observed from satellite and climate records," Geophysical Research Letters, vol. 30, no. 14, pp. 81-84, 2003.

[32] J. Grist, S. E. Nicholson, and A. Mpolokang, "On the use of NDVI for estimating rainfall fields in the Kalahari of Botswana," Journal of Arid Environments, vol. 35, no. 2, pp. 195-214, 1997. 